\title{
Isolation and Evaluation of Native Soil Bio-agents against Rhizoctonia solani Kuhn
}

\author{
Somshetty Ravali*, Bimla Rai and Prem Kumar Jha \\ Dr. Rajendra Prasad Central Agricultural University, Department of Plant Pathology, \\ Pusa, Samastipur, Bihar, India \\ *Corresponding author
}

\section{A B S T R A C T}

Keywords

Rhizoctonia solani, Rhizospreric mycoflora, Rhizobacteria, Antagonism and dual culture technique

Article Info

Accepted:

18 December 2020

Available Online:

10 January 2021
Seven rhizospheric myco-flora (Trichoderma harzianum, Trichoderma viride, Penicillium sp., three Aspergillus species and one was unknown) and four rhizobacteria (RB1- Pseudomonas fluorescence, RB2, RB3 and RB4) isolated from rhizosphere and were evaluated against sheath blight pathogen of rice Rhizoctonia solani Kuhn by dual culture technique. Among seven rhizospheric myco-flora $T$. harzianum has been shown highest growth inhibition $55.56 \%$ and has been followed by $T$. viride which produced $48.70 \%$. Remaining myco-flora were showed comparatively less growth inhibition. Among rhizobacteria RB1 (Pseudomonas fluorescence) and RB2 have produced noticeable amount of growth inhibition compared with others $20.86 \%$ and $9.30 \%$ respectively.

\section{Introduction}

Rhizoctonia solani Kuhn is the acceptable name for the sheath blight of rice fungus. $R$. solani was originally described by Julius Kuhn on potato in 1858 which the most widely documented and the most important destructive species of Rhizoctonia (Ogoshi, 1996). In 1963, Pracer and Chahal had first reported and described sheath blight of rice caused by Rhizoctonia solani Kuhn from Gurdaspur district of Punjab (Gangopadhyay and Chakrabarti, 1982).Under favourable conditions this disease becomes divesting and causes severe yield loss in rice. According to Dasgupta (1992), in Asia sheath blight resulting in $8-50 \%$ of yield losses, in case of moderate infection it was caused $5-15 \%$ yield loss (Annou et al., 2005) and under severe infestation it was leads to loss $30-40 \%$ (Kozaka, 1970).

In the market a plenty of chemicals are available for the control of sheath blight disease. But, it is known that lots of hazardous issues related to pesticides like fungicides and bactericides. So that, a head the naturally available beneficial microbes are 
known very well, they provide nutrition to plant, enhance the plant immunity by inducing resistant and are act as antagonist to several pathogens by inhibiting growth and development of the pathogen. It is important to study about microbial antagonist of $R$. solani the pathogen of sheath blight of rice. There is several research works have been going on antagonism of beneficial microbe against sheath blight pathogen, which is the most economically important disease of rice. Khan and Sinha (2007) have revealed that, Trichoderma harzianum and T. Viride was showed best growth inhibition of $R$. solani. Sixty rhizosphere bacterial strains were screened against sheath blight pathogen under in vitro condition, out of them, Pseudomonas fluorescens $(\mathrm{Tu}(\mathrm{Pf}) 19$ and $\mathrm{Kk}(\mathrm{Pf}) 24)$ and Bacillus subtilis ( $\mathrm{Tn}(\mathrm{Bs}) 7$ and $\mathrm{Kk}(\mathrm{Bs}) 19)$ were showed maximum growth inhibition of the pathogen (Nagendran et al., 2019).

Considering the importance of native bioagents in the present scenario, the current investigation was done on isolation and morphological identification of rhizospheric myco-flora and rhizobacteria and evaluation of efficacy of their antagonism against Rhizoctonia solani by dual culture technique.

\section{Materials and Methods}

The experiment on isolation and evaluation of native bio-agents against Rhizoctonia solani was conducted under laboratory condition at department of plant pathology, Dr. Rajendra Prasad Central Agricultural University, Pusa (Samastipur) -818425, Bihar, India.

\section{Isolation and purification of Rhizoctonia solani}

Diseased plant leaves were collected and washed in running tap water to remove any attached organic debris and dust particles. These were cut into pieces of 1-2 $\mathrm{mm}$ along with healthy tissue with use of sterilized blade. Pieces were dipped in $0.1 \%$ mercuric chloride about 30 seconds for the surface sterilization. Finally washed for three times in sterilized water and allowed to blotted dry. Under aseptic condition 2 to 3 pieces were transmitted to each media plate with use of heat sterilized inoculation needle and transferred plates allowed to incubation at 28 $\pm 1^{\circ} \mathrm{C}$. After $24-48$ hours of incubation active growing tips of hyphae were transferred to other new plates and pure culture was prepared by transferring single sclerotium on to PDA slants.

\section{Soil sample collection}

The healthy rice plants from research farm during Kharif (2019) were selected randomly and uprooted gently along with rhizospheric soil and dried under shade condition. Dried soil is collected from root surface mixed thoroughly, then removed pebbles and debris from that dried soil and it was sieved to get fine sample.

\section{Isolation and purification of native bio agents}

Soil sample collected from rhizosphere subjected to serial dilution. One gram of rhizosphere soil was transferred to $10 \mathrm{ml}$ of sterile water and mixed thoroughly. $1 \mathrm{ml}$ solution was taken from that suspension and mixed to next test tube with $9 \mathrm{ml}$ of sterile water to get $10^{-1}$ diluted sample. From this dilution $1 \mathrm{ml}$ transferred to another $9 \mathrm{ml}$ sterile water to get $10^{-2}$ diluted sample. This method was continued till getting $10^{-4}$ and $10^{-5}$ diluted sample. From the final dilutions of $^{10^{-4}}$ and $10^{-5}, 1 \mathrm{ml}$ of each was spread on PDA and Peptone dextrose rose Bengal agar medium to get rhizospheric mycoflora; it was also spread on King's B medium (for Pseudomonas isolation) and Nutrient agar 
medium to get rhizobacteria. The plates were gently rotated clockwise and anti-clockwise direction for uniform distribution of the soil suspension. The plates were finally allowed to incubation at $28 \pm 1^{\circ} \mathrm{C}$.

After 78 hours of inoculation fully grown colonies of fungi were obtained on media. To get pure culture of fungi active growing tips of hyphae were transferred to other new plates. After 28 hours bacterial colonies were formed on media. By using the inoculation loop different bacterial colonies were streaked on the fresh nutrient agar slants to obtain the pure culture. Rhizospheric myco-flora was identified based on their cultural and morphological characters. They were stained on slides with lacto phenol or cotton blue to observe their mycelial branching, conidial structure under microscope.

\section{Screening of native soil bio agents against Rhizoctonia solani Kuhn}

Antagonistic effect of rhizospheric microflora against Rhizoctonia solani was done by dual culture method. One side of PDA media containing Petri plates was inoculated with 9 $\mathrm{mm}$ disc of 2 to 3 days old culture of pathogen and another side transferred with disc of 5 days old culture of rhizospheric myco-flora; in case of bacteria another side was streaked with loop of 2 days old culture of rhizobacteria. Control plate was inoculated with pathogen without any soil micro-flora. Each treatment has been done with three replications. Inoculated plates were kept in BOD at $28 \pm 1{ }^{\circ} \mathrm{C}$. Readings were noted three times with 24 hours intervals and first reading was done at 72 hours after inoculation. By using following formula percentage growth inhibition of Rhizoctonia solani was calculated.

Percentage Growth Inhibition $=\frac{(\mathrm{C}-\mathrm{T}) \times 100}{\mathrm{C}}$
Where, $\quad \mathrm{C}=$ Radial growth of pathogen $(\mathrm{mm})$ in control plate.

$\mathrm{T}=$ Radial growth of pathogen $(\mathrm{mm})$ in dual culture.

\section{Statistical analysis}

The data obtained in the experiment was statistically analyzed using Completely Randomized Design (CRD) as per the procedures given by Snedecor and Cochran (1967) and Panse and Sukhatme (1985).

\section{Results and Discussion}

\section{Identification of rhizospheric micro-flora}

Seven rhizospheric myco-flora isolated from soil were identified based on their cultural and morphological characters (Figure I). Serial name for them has been given as RMF (Rhizospheric myco-flora).

RMF 1 (Trichoderma harzianum): Initially, colony was white in colour. Fully grown mycelium was thick and fuzzy. It was matured within 5 days and developed bluish green patches of conidia. Microscopic view revealed that, hypha was hyaline and septate. Conidiophores were erected and their branching usually opposite. Conidia were single celled with slightly sphere shape.

RMF 2 (Trichoderma viride): Initially, colony was white in colour, later it was appeared like yellowish green due to pigmentation, and was smooth and leathery to naked eye. Hypha was hyaline and septate. Conidia were one celled and bigger than T. Harzianum. Phialides were irregular and less crowned. Conidiophores were irregularly branched.

RMF 3 (Aspergillus sp.): Colonies on PDA were beige to buff to cinnamom in colour. Yellow pigmentation was observed at lower 
side of the Petri plate. Colonies became finely granular with conidial production. Under microscope conidial heads were look like biseriate. Conidiophore was hyaline with soft wall. Conidium was hyaline and sphere shaped.

RMF 4 (Penicillium sp.): Colonies were initially white in colour, later become bluish green and were flat, filamentous and velvet in texture. Yellow to orange pigmentation was observed at lower side of the Petri plate. Hyphae were hyaline, branched and septate. Conidia were single celled; circular shaped, appeared in chain, and farmed brush like structures. Conidiophore was erected, branched, septete, and metula was formed on it.

RMF 5 (Aspergillus sp.): Colonies on PDA were initially white in colour, round to oval in shape. It quickly became dull greenish and later turned into yellowish green with loose surface. Pale yellow colour was shown on reverse of the Petri plate.

RMF 6 (Unknown): Initially, small circular and white coloured colonies were formed. Later they turned to light green colour. Mycelium was hyaline. Conidiophore was long and cylindrical.

RMF 7 (Aspergillus sp.): Colonies were suede-like to floccose, white to pale yellow with slow to poor condition and were grown very slowly. Conidial heads were short, columnar and unseriate. Conidiophore stipes smooth walled and vesicles were subglobose to flask shaped and conidia globose to sub globose.

Four different rhizobacteria were isolated based on variation in their colony morphology and have been named as RB (Rhizobacteria). Among these, RB 1 is Pseudomonas fluorescence which was isolated on King's B medium and has illuminate property under the light (Figure II).

Table.1 Effect of various rhizospheric myco-flora on radial growth and percent growth inhibition of $R$. solani at different time intervals

\begin{tabular}{|c|c|c|c|c|c|c|}
\hline \multirow{2}{*}{$\begin{array}{l}\text { Rhizospheric } \\
\text { mycoflora }\end{array}$} & \multicolumn{2}{|c|}{72 hours } & \multicolumn{2}{|c|}{96 hours } & \multicolumn{2}{|c|}{120 hours } \\
\hline & $\mathbf{G}$ & I & $\mathbf{G}$ & I & $\mathbf{G}$ & I \\
\hline RMF 1 & 38.67 & 46.30 & 40.00 & 55.56 & 40.00 & 55.56 \\
\hline RMF 2 & 46.17 & 35.88 & 46.17 & 48.70 & 46.17 & 48.70 \\
\hline RMF 3 & 66.67 & 7.41 & 81.17 & 9.81 & 81.17 & 9.81 \\
\hline RMF 4 & 70.83 & 1.62 & 80.33 & 10.74 & 80.33 & 10.74 \\
\hline RMF 5 & 63.33 & 12.04 & 75.67 & 15.93 & 75.67 & 15.93 \\
\hline RMF 6 & 68.33 & 5.09 & 82.67 & 8.15 & 82.67 & 8.15 \\
\hline RMF 7 & 55.33 & 23.15 & 69.00 & 23.33 & 69.00 & 23.33 \\
\hline Control & 72.00 & 0.00 & 90.00 & 0.00 & 90.00 & 0.00 \\
\hline CD at $5 \%$ & \multicolumn{2}{|c|}{1.357} & \multicolumn{2}{|c|}{1.054} & \multicolumn{2}{|c|}{1.008} \\
\hline SEm \pm & \multicolumn{2}{|c|}{0.449} & \multicolumn{2}{|c|}{0.349} & \multicolumn{2}{|c|}{0.333} \\
\hline C.V. & \multicolumn{2}{|c|}{1.292} & \multicolumn{2}{|c|}{0.855} & \multicolumn{2}{|c|}{0.891} \\
\hline
\end{tabular}

RMF -Rhizospheric myco-flora; G- Radial growth (mm); I- Per cent growth inhibition 
Table.2 Effect of various rhizobacteria on radial growth and percent growth inhibition of $R$. solani at different time intervals

\begin{tabular}{|l|c|c|c|c|c|c|}
\hline \multirow{2}{*}{ Rhizobacteria } & \multicolumn{2}{|c|}{ 72 hours } & \multicolumn{2}{c|}{ 96 hours } & \multicolumn{2}{c|}{ 120 hours } \\
\cline { 2 - 8 } & G & I & G & I & G & I \\
\hline RB 1 & 71.23 & 1.07 & 71.23 & 20.86 & 71.23 & 20.86 \\
\hline RB 2 & 72.00 & 0.00 & 90.00 & 0.00 & 90.00 & 0.00 \\
\hline RB 3 & 71.83 & 0.23 & 81.63 & 9.30 & 81.63 & 9.30 \\
\hline RB 4 & 72.00 & 0.00 & 90.00 & 0.00 & 90.00 & 0.00 \\
\hline Control & 72.00 & 0.00 & 90.00 & 0.00 & 90.00 & 0.00 \\
\hline CD at 5\% & \multicolumn{2}{|c|}{0.070} & \multicolumn{2}{c|}{0.067} & \multicolumn{2}{c|}{0.067} \\
\hline SEm \pm & \multicolumn{2}{|c|}{0.199} & \multicolumn{2}{c|}{0.229} & \multicolumn{2}{c|}{0.229} \\
\hline C.V. & \multicolumn{2}{|c|}{0.480} & \multicolumn{2}{c|}{0.480} & \multicolumn{2}{c|}{0.480} \\
\hline
\end{tabular}

RB -Rhizobacteria; G- Radial growth (mm); I- Inhibition per cent

Fig.1 Rhizospheric myco-flora

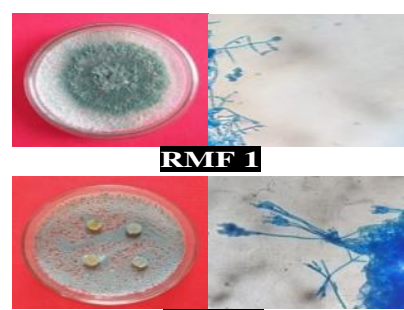

RMF 4

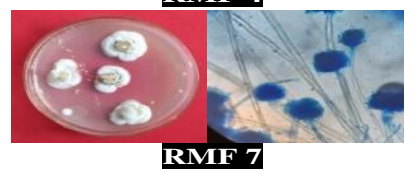

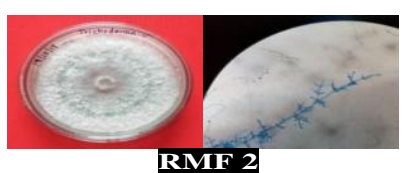

RMF 2

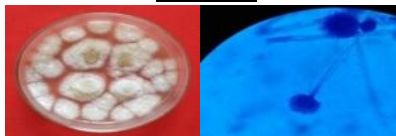

RMF 5

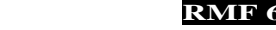

RMF- Rhizospheric myco-flora, RMF 1 -Trichoderma

harzianum, RMF 2 -Trichoderma viride, RMF 3 -

Aspergillus sp., RMF 4-Penicillium sp., RMF 5-Aspergillus sp., RMF 6-Unknown, RMF 7 -Aspergillus sp.

Fig.2 Rhizobacteria

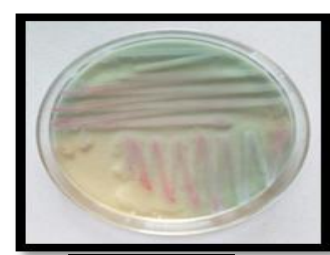

RB 1

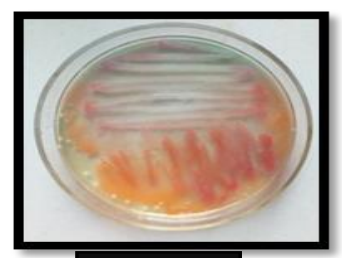

RB 3

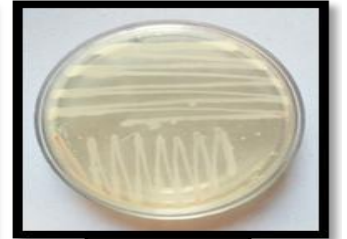

RB 2

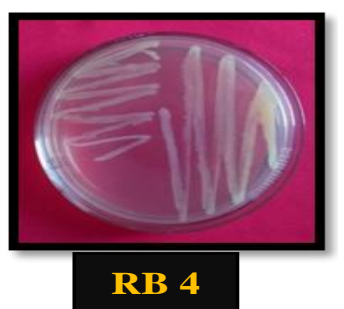


Fig.3 Antagonistic effect of rhizospheric myco-flora on growth of $R$. solani at different time intervals
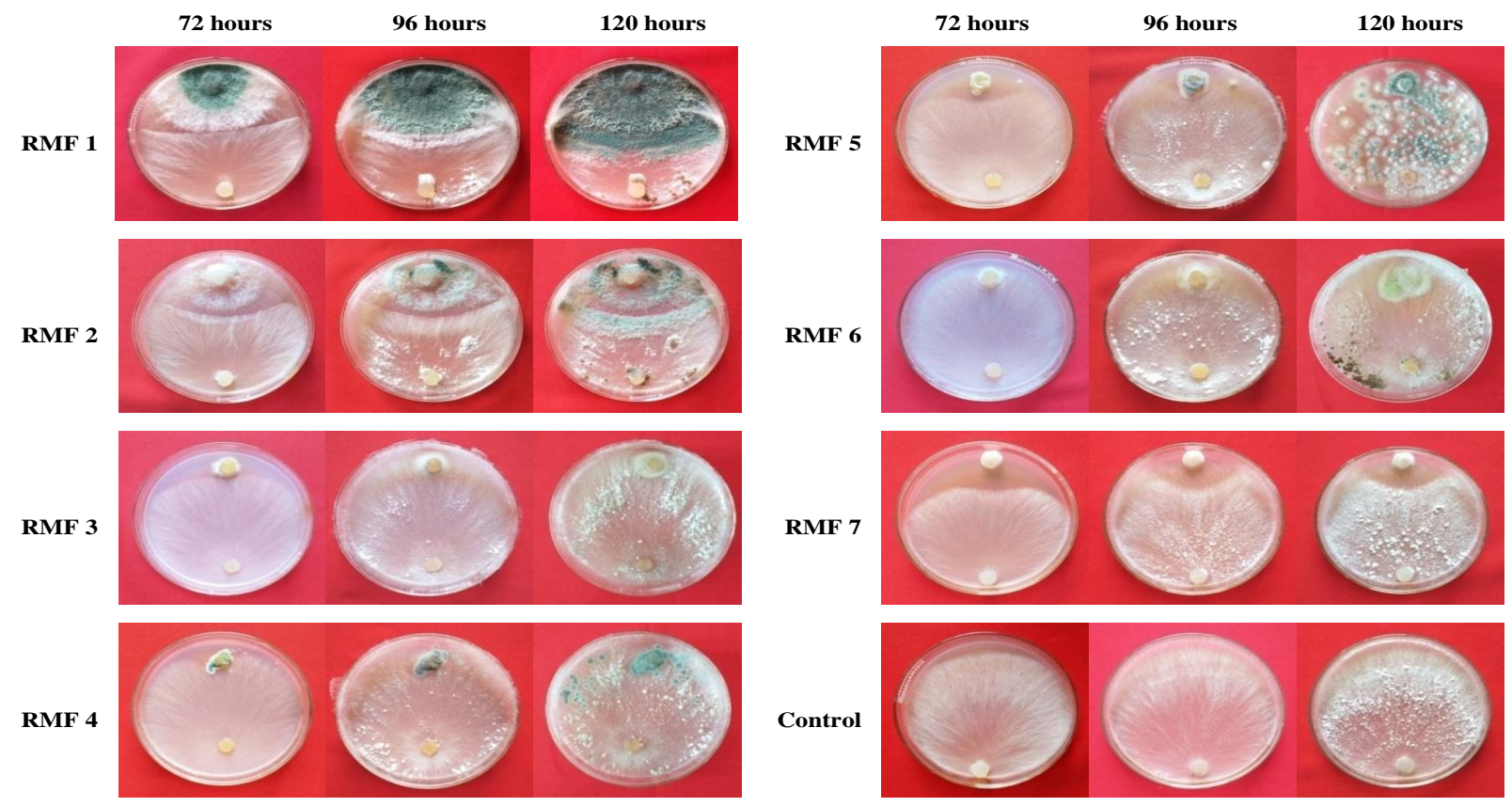

Fig.4 Antagonistic effect of rhizobacteria on growth of $R$. solani at different time intervals

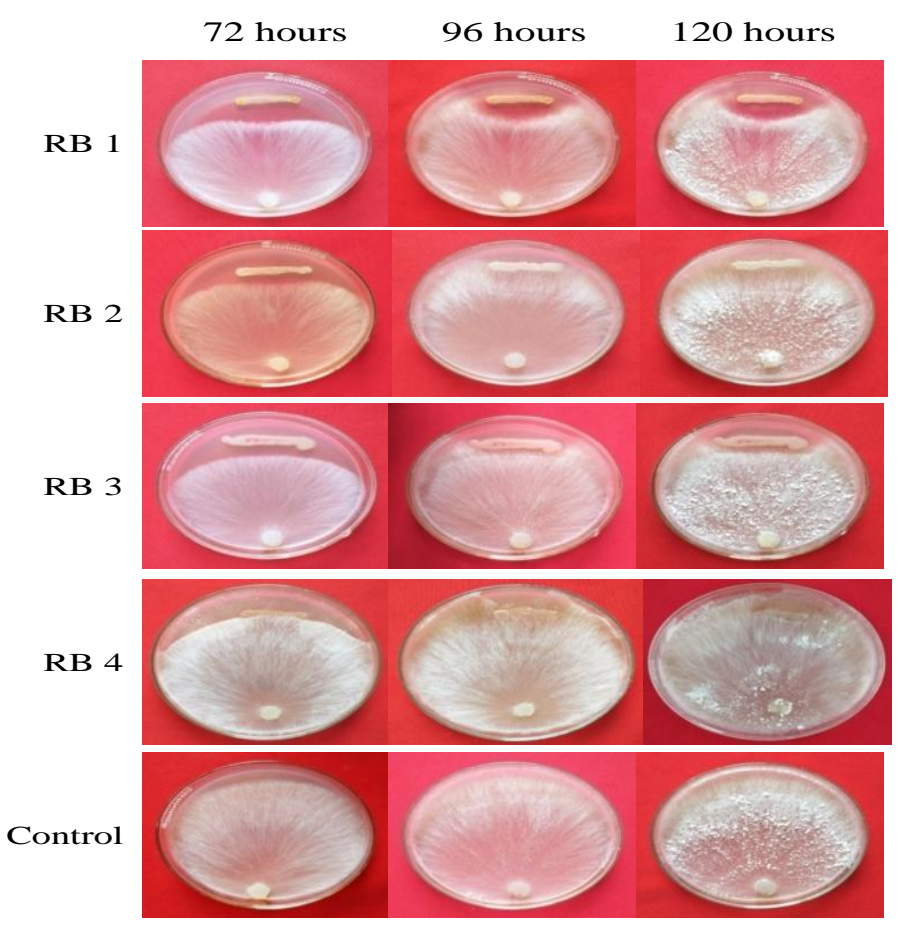


Evaluation of rhizospheric myco-flora against $R$. solani

Seven native mycoflora were evaluated contrary to $R$. solani by dual culture method. Data on radial growth of the $R$. solani has been taken at 72, 96 and 120 hours after inoculation. Readings on the radial growth $(\mathrm{G}$ in $\mathrm{mm}$ ) and per cent growth inhibition (I) have been provided in Table 1 and visualized in Figure III.

Data presented in Table 1 revealed that all rhizospheric myco-flora examined had antagonistic nature against Rhizoctonia solani, they were exhibited $1.62 \%$ to $46.30 \%$, $8.15 \%$ to $55.56 \%$ and $9.81 \%$ to $55.56 \%$ growth inhibition of $R$. solani after 72, 96 and 120 hours of inoculation respectively. Among these, RMF 1 (Trichoderma harzianum) had maximum antagonistic effect on pathogen compared to other rhizospheric myco-flora, it produced $46.30 \%, 55.56 \%$ and $55.56 \%$ of inhibition after 72,96 and 120 hours of inoculation respectively.

Next best antagonist was RMF 2 (T. viride) which produced $48.7 \%$ of growth inhibition after 120 hours of inoculation. Remaining rhizospheric myco-flora were showed less effective against $R$. solani, they were produced less than $25 \%$ of growth inhibition after 120 hours after inoculation (RMF 3 (9.81\%), RMF 4 (10.74\%), RMF 5 (15.93\%), RMF 6 (8.15) and RMF 7 (23.33\%)).

Ali and Nadarajah (2013) noted that out of the twenty isolates of Trichoderma, isolates 2, 6 , $7,8,20,13,17$ and 22 were most antagonistic to $R$. solani. Lenka et al., (2012) evaluated several isolates of Trichoderma against $R$. solani and stated $T$. Viride (Bangalore isolate) was highly inhibited growth of mycelia and sclerotium formation. Next best were Bangalore isolate T. harzianum and Bhubaneswar isolate T. viride. Naeimi et al.,
(2010) have isolated more than 200 Trichoderma isolates, screened contrary to $R$. solani. Noted isolates $T$. harzianum, $T$. virens and $T$. atroviride showed better antagonism. Khan and Sinha (2007) have revealed that, Trichoderma harzianum was showed best growth inhibition of $R$. solani and next to it was $T$. Viride.

Screening of rhizobacteria for their antagonistic activity against $R$. solani by dual culture method

Four different rhizobacteria were isolated based on variation in their colony morphology and they were evaluated for their antagonistic effect against rice pathogen $R$. solani by dual culture technique. Radial growth of the $R$. solani has been taken after 72, 96 and 120 hours of inoculation. Readings on the radial growth ( $\mathrm{G}$ in $\mathrm{mm}$ ) and per cent growth inhibition (I) have been provided in Table 2 and visualized in Figure IV.

Date presented on Table 2 revealed that rhizobacteria RB1 (Pseudomonas fluorescence) had maximum antagonistic effect on $R$. solani as $20.86 \%$ of growth inhibition after 120 hours of inoculation compared with other rhizobacteria it has shown least antagonistic effect on pathogen.

Ahmed et al., (2019) have screened five isolates of Pseudomonas fluorescens contrary to $R$. solani, which were isolated from rhizosphere. The isolate Pf 2 has shown 40.66 per cent inhibition compared to control. Maximum percent inhibition of sclerotia (88.64 per cent) and their dry weight also reduced to 82.72 per cent was observed when isolates Pf 2 was allowed to grow with $R$. solani. Nagendran et al., (2019) have experimented sixty rhizosphere bacterial strains against sheath blight pathogen in in vitro condition, among the bacterial strains, Pseudomonas fluorescens $\mathrm{Tu}(\mathrm{Pf}) 19$ and 
$\mathrm{Kk}(\mathrm{Pf}) 24$ and Bacillus subtilis $\mathrm{Tn}(\mathrm{Bs}) 7$ and $\mathrm{Kk}(\mathrm{Bs}) 19$ were showed maximum growth inhibition. Suman et al., (2017) have isolated thirty native fluorescent Pseudomonas sp. and have screened them contrary to $R$. solani.

Among all three strains DMP1 (53.43\%), DBP $(51.53 \%)$ and PVP2 (48.26\%) have been shown best growth inhibition results. Abdelbary et al., (2015) have separated 17 isolates of $P$. fluorescence from rhizosphere. Among these Pf14 has shown maximum growth inhibition of Rhizoctonia solani as $60.49 \%$.

In conclusion the results it can be say that, a total of twelve native soil bio agents (seven were rhizospheric mycoflora and four were rhizobacteria) were isolated and screened against sheath blight pathogen by dual culture method. All rhizospheric myco-flora have been shown a countable amount of antagonistic effect against mycilial growth of Rhizoctonia solani Kuhn; among these RMF1 (Trichoderma harzianum) and RMF2 (Trichoderma viride) showed best antagonism against Rhizoctonia solani as $55.56 \%$ and $48.70 \%$ of growth inhibition respectively after 120 hours of inoculation compared to control and remaining mycoflora were produced growth inhibition bellow 25\%. Among four rhizobacteria, two were showed $20.86 \%$ (RB1-Pseudomonas fluorescence) and $9.30 \%$ (RB3) of growth inhibition and other two have been produced zero growth inhibition against sheath bight pathogen.

\section{Acknowledgement}

I humbly extend my profound gratitude to my advisory committee members and professors, Department of Plant Pathology, College of Agriculture, Pusa, Samastipur, Bihar for their constant support and valuable suggestions offered during the course of research work.

\section{References}

Abdelbary, A. I., Heflish, I. and Singh, N. (2015). Potential of native strains of Pseudomonas fluoresces against Rhizoctonia solani and Rhizoctonia oryzae causing sheath blight of rice. Plant Disease Research. 29(2): 488495.

Ahmed, T., Ali, S. and Das, A. (2019). In vitro Efficacy of Indigenous Pseudomonas Fluorescens isolates Against Rhizoctonia Solani. International Journal of Recent Scientific Research. 10(07): 3398433986.

Ali, H. Z., and Nadarajah, K. (2013). Evaluating the efficacy of Trichoderma isolates and Bacillus subtilis as biological control agents against Rhizoctonia solani. Research Journal of Applied Sciences. 8(1): 7281.

Annou, M. M., Wailes, E. J and Thomsen, M. R. (2005). A dynamic decision model of technology adoption under uncertainty: case of herbicide-resistant rice. Journal of Agricultural and Applied Economics. 37: 161-172.

Dasgupta, M. K. 1992. Rice sheath blight: The challenge continues in: Plant Diseases of International Importance: Diseases of Cereals and Pulses. New India Publishing Agency,115 pp.

Gangopadyay, S and Chakrabarti, N. K. (1982). Sheath blight on rice. Review of Plant Pathology. 61: 451-460.

Khan, A. A. and Sinha, A. P. (2007). Screening of Trichoderma spp. against Rhizoctonia solani the causal agent of rice sheath blight. Indian Phytopathology. 60(4): 450-456.

Khan, A. A. and Sinha, A. P. (2007). Screening of Trichoderma spp. against Rhizoctonia solani the causal agent of rice sheath blight. Indian 
Phytopathology. 60(4): 450-456.

Kozaka, T. (1970). Yeild loss due to sheath blight. Japan Agricultural Research. 512-516.

Lenka, S., Mishra, S. K., Mohanty, S. K., Das, K. M., and Medhi, B. (2012). Bio-control of rice sheath blight through antagonists. ORYZA-An International Journal on Rice, 49(1): 68-69.

Naeimi, S., Okhovvat, S. M., Javan-Nikkhah, M., Vágvölgyi, C., Khosravi, V. and Kredics, L. (2010). Biological control of Rhizoctonia solani AG1-1A, the causal agent of rice sheath blight with Trichoderma strains. Phytopathologia Mediterranea. 49(3): 287-300.

Nagendran, S., Kulanthaivelu, S. and Sundararajan, T. (2019). Assessment on antagonistic potential of Bacterial bio agents Pseudomonas fluorescens and Bacillus subtilis against
Rhizoctonia solani Kühn. An incitant of Sheath blight of rice.

Ogoshi, A. 1996. Introduction - the genus Rhizoctonia solani. In: Sneh B, JabajiHare S, Neate SM, Dijst G (eds), Rhizoctonia species, Taxonomy, Molecular Biology, Ecology, Pathology and Disease Control. Kluwer, Dordrecht, pp. 1-9.

Paracer, C.S. and Chahal, D.S. (1963). Sheath blight of rice caused by Rhizoctonia solani Kuhn- A new record in India. Current Sciences. 32: 328-329.

Suman, B., VijayaGopal, A., Subhash Reddy, R., Triveni, S. and Nissipaul, $M$. (2017). Study the Efficacy of Pseudomonas fluorescens against Sheath Blight in Rice by Rhizoctonia solani. International Journal of Current and Microbiology Applied Sciences. 6(4): 2581-2589.

\section{How to cite this article:}

Somshetty Ravali, Bimla Rai and Prem Kumar Jha. 2021. Isolation and Evaluation of Native Soil Bio-agents against Rhizoctonia solani Kuhn. Int.J.Curr.Microbiol.App.Sci. 10(01): 26952703. doi: https://doi.org/10.20546/ijcmas.2021.1001.313 